NBER WORKING PAPER SERIES

\title{
THE IMPACT OF NEW DRUG LAUNCHES ON LONGEVITY: EVIDENCE FROM LONGITUDINAL, DISEASE-LEVEL DATA FROM 52 COUNTRIES, 1982-2001
}

\author{
Frank R. Lichtenberg \\ Working Paper 9754 \\ http://www.nber.org/papers/w9754

\begin{abstract}
NATIONAL BUREAU OF ECONOMIC RESEARCH 1050 Massachusetts Avenue Cambridge, MA 02138
\end{abstract} \\ June 2003
}

The views expressed herein are those of the authors and not necessarily those of the National Bureau of Economic Research.

C2003 by Frank R. Lichtenberg. All rights reserved. Short sections of text not to exceed two paragraphs, may be quoted without explicit permission provided that full credit including $\odot$ notice, is given to the source. 
The impact of new drug launches on longevity: evidence from longitudinal, disease-level data from 52 countries, 1982-2001

Frank R. Lichtenberg

NBER Working Paper No. 9754

June 2003

JEL No. I12, F00, L65, O3, O4

\begin{abstract}
We perform an econometric analysis of the effect of new drug launches on longevity, using data from the IMS Health Drug Launches database and the WHO Mortality Database. Our data cover virtually all of the diseases borne by people in 52 countries during the period 1982-2001, and enable us to control, to an unusually great extent, for the effects of other potential determinants of longevity, e.g. education, income, nutrition, the environment, and "lifestyle". We find that launches of new chemical entities (NCEs) have a strong positive impact on the probability of survival. Launches of (older) drugs that are not NCEs do not increase longevity. NCE launches account for a significant fraction of the long-run increase in longevity in the sample as a whole. Between 1986 and 2000, average life expectancy of the entire population of sample countries increased by almost two years. Our estimates imply that NCE launches accounted for 0.8 years (40\%) of the 1986-2000 increase in longevity. The average annual increase in life expectancy of the entire population resulting from NCE launches is .056 years, or 2.93 weeks.

Frank R. Lichtenberg

Graduate School of Business

Columbia University

726 Uris Hall

3022 Broadway

New York, NY 10027

and NBER

frank.lichtenberg@columbia.edu
\end{abstract}


Longevity has increased throughout the world during the last half century. According to the United Nations, life expectancy at birth increased from 46.5 years in 1950-55 to 65.0 years in 1995-2000 (Figure 1). ${ }^{1}$ The rate of increase in the last quarter of the $20^{\text {th }}$ century was only half as great as the rate of increase in the previous quarter; still, life expectancy at birth increased 5.2 years from 1975-1980 to 1995-2000. Moreover, longevity in less-developed regions has grown much more rapidly than longevity in more developed regions (Figure 2). In the last two decades, the gap has narrowed by 3.5 years. Unlike per capita income, longevity is converging.

Until recently, there appears to have been a consensus among health economists (or at least authors of health economics textbooks) that the contribution of medical care to longevity increase and other health improvements has been quite modest. Consider these quotations from four textbooks:

the empirical evidence indicates [that] the overall contribution of medical care to health is rather modest at the margin...education, lifestyle, the environment, and income [are] the major contributing factors (Santerre and Neun (2000, p. 69)).

increase in life expectancy [has] been much more influenced by economic development than improvements in medical care...the most important medical advances are being brought about by improvements in information technology, not pills and scalpels (Getzen (1997, p. 330)).

Research on the relationship between health status and medical care frequently has found that the marginal contribution of medical care to health status is rather small... any significant improvements in health status are more likely to originate from factors other than medical care...Factors that determine the level of health include income and education, environmental and life-style factors, and genetics (Henderson (1999, p.142)).

The historical declines in population mortality rates were not due to medical interventions because effective medical interventions became available to populations largely after the mortality had declined. Instead, public health, improved environment, and improved nutrition probably played substantial roles (Folland, Goodman, and Stano (2001, p. 118)).

\footnotetext{
${ }^{1}$ Referring to the U.S., Nordhaus (2002, p. 17) estimated that, "to a first approximation, the economic value of increases in longevity over the twentieth century is about as large as the value of measured growth in non-health goods and services."
} 
But some recent research has indicated that technological innovations in medicine have had important positive impacts on health. Cutler and McClellan (2001) reviewed case studies of technological change in the treatment of five conditions (heart attack, lowbirthweight infants, depression, cataracts, and breast cancer) in the U.S. They concluded that "in most of the cases we analyzed, technological innovations in medicine are on net positive. Technology often leads to more spending, but outcomes improve by even more" (p. 23).

In this paper, we will perform an econometric analysis of the effect of new drug launches on longevity. Bresnahan and Gordon(1997) argue that "new goods are at the heart of economic progress." Investment in research and development (R\&D) is a prerequisite for new good development, and the pharmaceutical industry is the most research-intensive industry in the economy. Drugs are much more research-intensive than most other goods and services utilized in the health care sector. As the data in the following table show, in the U.S. in 1995 pharmaceutical industry R\&D expenditure accounted for almost a third of total health $R \& D$ expenditure and more than half of industry health R\&D expenditure.

\begin{tabular}{|l|r|}
\hline Total health R\&D expenditure & $\$ 35.8$ billion \\
\hline Industry health R\&D expenditure & $\$ 18.6$ billion \\
\hline Pharmaceutical industry R\&D expenditure (NSF estimate) & $\$ 10.2$ billion \\
\hline Pharmaceutical industry R\&D expenditure (PhRMA estimate) & $\$ 11.9$ billion \\
\hline
\end{tabular}

Clinical studies of specific drugs have shown that these drugs increase longevity. Here are three examples:

- Stenestrand et al (2001) studied the impact on survival of statin treatment following acute myocardial infarction. They found that 1-year mortality was $9.3 \%$ in the no-statin group and $4.0 \%$ in the statin treatment group.

- Grier et al (2003) found that adding two experimental drugs to the standard fourdrug chemotherapy regimen has significantly improved survival in patients with non-metastatic Ewing's sarcoma, a highly malignant bone cancer of children and young adults. The overall survival rate increased from 61 percent to 72 percent for Ewing's sarcoma patients with localized disease who underwent the experimental six-drug chemotherapy.

- The journal U.S. Pharmacist (2002) reported that patients suffering from advanced metastatic melanoma who were treated with a combination of an 
investigational agent, Ceplene, and interle ukin-2 (IL-2) had twice the survival rate as patients who were treated with IL- 2 only. The patients were enrolled in a threeyear study. The study also showed that the Ceplene/IL-2 combination significantly increased survival in a subpopulation group of advanced metastatic melanoma patients with liver metastases. The rate of survival in this group was six times that of the group given IL-2 only.

My objective is to assess the average or aggregate contribution of all new drug introductions. The data I will analyze cover all of the drugs introduced in, and diseases borne by people in, 52 countries during the period 1982-2001. Fortunately, launches of new drugs in these countries have been carefully tracked since 1982 by IMS Health. ${ }^{2}$ Moreover, we can determine the (primary) disease associated with each new drug. Hence, we can measure the entry of new drugs, by disease, country, and year. Using data from the World Health Organization, we can also measure mortality (the age distribution of deaths) by disease, country, and year. Analysis of the relationship between new drug launches and mortality using longitudinal, disease-level data from 52 countries enables us to control, to an unusually great extent, for the effects of other potential determinants of mortality, e.g. education, income, nutrition, the environment, and "lifestyle".

The remainder of this paper is organized as follows. Section I outlines an econometric framework. Measurement issues and data sources are discussed in Section II. Empirical results are presented in Section III. Implications of the estimates are discussed in Section IV. Section V contains a summary.

\section{Econometric framework}

We hypothesize that the age distribution of deaths from disease $i$ in country $j$ in year $\mathrm{t}$ depends on the number of drugs launched to treat disease $\mathrm{i}$ in country $\mathrm{j}$ by year $\mathrm{t}-\mathrm{k}$, and on other factors:

$$
\text { AGE_DEATH } H_{\mathrm{ijt}}=\beta \ln \left(\mathrm{N} \_D R U G_{\mathrm{ij}, \mathrm{t}-\mathrm{k}}\right)+\gamma \mathrm{X}_{\mathrm{ijt}}+\varepsilon_{\mathrm{ijt}}
$$

where

AGE_DEATH $\mathrm{ijt}_{\mathrm{ijt}}=\mathrm{a}$ statistic based on the age distribution of deaths from disease $\mathrm{i}$ in country $\mathrm{j}$ in year $\mathrm{t}$

\footnotetext{
${ }^{2}$ Corresponding data on the launch of non-drug medical innovations (e.g. medical devices or surgical procedures) do not seem to be available.
} 
N_DRUG $\mathrm{ij}_{\mathrm{j}, \mathrm{t}-\mathrm{k}}=$ the number of drugs launched to treat disease $\mathrm{i}$ in country $\mathrm{j}$ by year $\mathrm{t}-\mathrm{k}$

$\mathrm{X}_{\mathrm{ijt}}=\mathrm{a}$ vector of other factors (e.g. education, income, nutrition, the environment, and "lifestyle") affecting the age distribution of deaths from disease $i$ in country $j$ in year $\mathrm{t}$

Eq. (1) may be viewed as a health production function. AGE_DEATH is an indicator of "health output". N_DRUG may be viewed as an indicator of the level of medical technology. ${ }^{3}$ We specify AGE_DEATH to be a function of the logarithm of N_DRUG because we hypothesize that there are diminishing returns to additions to the stock of drugs. We specify a k-year lag in the relationship to allow for gradual diffusion of new drugs to consumers; we will estimate the model using different assumed values of $\mathrm{k}(\mathrm{k}=0,1,2, \ldots)$.

We hypothesize that many of the "other factors" affecting the age distribution of deaths from disease $\mathrm{i}$ in country $\mathrm{j}$ in year $\mathrm{t}$ (e.g. per capita income, public health expenditure, and environmental quality) are invariant across diseases within a country and year, invariant across countries within a disease and year, or invariant across years within a country and disease. For biological reasons, people tend to die at younger ages from some diseases than from others in a given year, in all countries. For economic and other reasons, people tend to die at younger ages in some countries than in others in a given year, from all diseases.

Without loss of generality, we can decompose $\mathrm{X}_{\mathrm{ijt}}$ as follows:

$$
\mathrm{X}_{\mathrm{ijt}}=\alpha^{\prime}{ }_{\mathrm{it}}+\delta^{\prime}{ }_{\mathrm{jt}}+\theta^{\prime}{ }_{\mathrm{ij}}+v^{\prime}{ }_{\mathrm{ijt}}
$$

where

$$
\begin{aligned}
& \alpha^{\prime}{ }_{\mathrm{it}}=\text { a fixed effect for disease } \mathrm{i} \text { in year } \mathrm{t} \\
& \delta_{\mathrm{jt}}^{\prime}=\mathrm{a} \text { fixed effect for country } \mathrm{j} \text { in year } \mathrm{t} \\
& \theta^{\prime}{ }_{\mathrm{ij}}=\mathrm{a} \text { fixed effect for disease } \mathrm{i} \text { in country } \mathrm{j}
\end{aligned}
$$

\footnotetext{
${ }^{3}$ In his model of endogenous technological change, Romer (1990) hypothesized the production function $\mathrm{Y}$ $=(\mathrm{A} \mathrm{L})^{1-\alpha} \mathrm{K}^{\alpha}$, where $\mathrm{Y}=$ output, $\mathrm{A}=$ the "stock of ideas", $\mathrm{L}=$ labor used to produce output, $\mathrm{K}=$ capital, and $0<\alpha<1$. The cumulative number of drugs launched (N_DRUG) is analogous to the stock of ideas.
} 
Substituting (2) into (1),

where

$$
\begin{aligned}
\text { AGE_DEATH }_{\mathrm{ijt}} & =\beta \ln \left(\mathrm{N}_{-} \mathrm{DRUG}_{\mathrm{ij}, \mathrm{t}-\mathrm{k}}\right)+\gamma\left(\alpha^{\prime}{ }_{\mathrm{it}}+\delta^{\prime}{ }_{\mathrm{jt}}+\theta^{\prime}{ }_{\mathrm{ij}}+v^{\prime}{ }_{\mathrm{ijt}}\right)+\varepsilon_{\mathrm{ijt}} \\
& =\beta \ln \left(\mathrm{N}_{-} \mathrm{DRUG} \mathrm{i}_{\mathrm{ij}, \mathrm{t}-\mathrm{k}}\right)+\alpha_{\mathrm{it}}+\delta_{\mathrm{jt}}+\theta_{\mathrm{ij}}+\mathrm{u}_{\mathrm{ijt}}
\end{aligned}
$$

$$
\begin{aligned}
& \alpha_{\mathrm{it}}=\gamma \alpha^{\prime}{ }_{\mathrm{it}} \\
& \delta_{\mathrm{jt}}=\gamma \delta^{\prime}{ }_{\mathrm{jt}} \\
& \theta_{\mathrm{ij}}=\gamma \theta^{\prime}{ }_{\mathrm{ij}} \\
& \mathrm{u}_{\mathrm{ijt}}=\left(\gamma v^{\prime}{ }_{\mathrm{ijt}}+\varepsilon_{\mathrm{ijt}}\right)
\end{aligned}
$$

For example, suppose, as previous authors have argued, that environmental quality is an important determinant of AGE_DEATH, and also that environmental quality is correlated with N_DRUG. If environmental quality is invariant across diseases within a country and year, then its effect on AGE_DEATH is completely controlled for by $\delta_{\mathrm{jt}}$. If environmental quality varies across diseases, but deviations from country-year means are constant over time, then its effect on AGE_DEATH is completely controlled for by $\delta_{\mathrm{jt}}$ and $\theta_{\mathrm{ij}}$. If environmental quality varies across diseases, and deviations from country-year means are not constant over time, estimates of $\beta$ will be consistent as long as the deviation of environmental quality from its mean deviation from country-year means is uncorrelated with the deviation of $\ln \left(\mathrm{N}_{-} \mathrm{DRUG}_{\mathrm{ij}, \mathrm{t}-\mathrm{k}}\right)$ from its mean deviation from country-year means. The same argument applies to other potential determinants of AGE_DEATH (income, education, etc.).

While we can measure the stock of drugs by disease, country, and year, due to data limitations, we cannot measure the availability of medical devices (or of diagnostic surgical procedures). If changes in the stock of devices are uncorrelated across diseases with changes in the stock of drugs, the drug-stock coefficient is unbiased. If changes in the stocks of devices and drugs are correlated (controlling for the fixed effects in eq. (3)), the drug-stock coefficient could be biased. The direction of bias depends on the sign of the correlation. If the change in the stock of devices is negatively correlated across diseases with the change in the stock of drugs, the drug-stock coefficient is downward 
biased. Some evidence suggests that this correlation may indeed be negative.

Lichtenberg $(1996,2001)$ presented evidence that use of newer drugs is associated with lower utilization of hospital care. Since use of some medical devices, such as stents and artificial hearts, requires hospitalization, drugs and devices may be substitutes rather than complements. Moreover, according to the Agency for Healthcare Research and Quality (2002), in 1999 the number of Americans using prescription drugs (172 million) was over eight times as large as the number with any hospitalizations (20 million).

If pharmaceutical companies are more likely to launch drugs in product/geographic markets where they will have the largest impact on AGE_DEATH, then eq. (3) could result in an overestimate of the average longevity impact of new drug launches. While this possibility cannot be entirely ruled out, there are reasons to doubt substantial overestimation of the average longevity impact. First, previous studies of the determinants of drug launch have not found any evidence that pharmaceutical companies are more likely to launch drugs in product/geographic markets where they will have the largest impact on AGE_DEATH: Danzon et al (2003) and Kyle (2003) both found that market size (population) and the regulatory regime are important determinants of the probability of drug launch. ${ }^{4}$ Second, if pharmaceutical firms tend to launch in markets where the benefit of launch is greatest, they are likely to launch in markets with the highest total, rather than average, longevity benefit. Suppose that the expected effect of a new leukemia drug on mean age at death in country A is 6 months, and that the expected effect in country B is 1 month. If 10 times as many people suffer from leukemia in country B as do in country A, then the social (and presumably private) benefits to launch in country B is higher, even though the benefit per patient is lower. Changes in AGE_DEATH reflect the average, rather than total, longevity benefit.

\footnotetext{
${ }^{4}$ These determinants are likely to be well controlled for by the fixed effects in eq. (3). Kyle found that firm characteristics (e.g. whether the firm was a domestic firm) and other factors also played a role.
} 


\section{Measurement}

\section{Drug launches}

We used data from the IMS Health Drug Launches database ${ }^{5}$ to construct estimates of the number of drugs launched to treat disease $\mathrm{i}$ in country $\mathrm{j}$ by year $\mathrm{t}-\mathrm{k}$. This database has tracked new product introductions worldwide since 1982. In August 2001 the database contained over 165,000 records of individual product introductions between 1982 and 2001. 72 countries are covered; many have been tracked since 1982. Data on product introductions is gathered from the IMS Health network of offices around the world and reflects the information on the product at the time of launch into each country.

Each record in the database contains the following information: the date and country of product launch, the active ingredient(s) of the product, a dummy variable indicating whether the product's ingredient is a new chemical entity (i.e. whether no products containing this ingredient have been launched anywhere before), and the therapeutic class of the product. The IMS therapeutic classification is extremely detailed; we recoded (aggregated) therapeutic classes into 11 therapeutic areas (e.g. nervous system drugs, respiratory drugs).

We constructed a list of all of the ingredients occurring in the database. This list contained information about two ingredient attributes: (1) whether the ingredient was a new chemical entity (i.e. was not launched anywhere in the world before 1982), and (2) the therapeutic area most frequently associated with the ingredient. ${ }^{6}$

We also constructed, for each country, a list of the active ingredients contained in products launched anytime during 1982-2002, and the first year in which that ingredient was observed in that country. We then merged the list of ingredients by country with the list of ingredient attributes. This enabled us to determine, for each country and therapeutic area, the total number of ingredients launched, and the number of new chemical entities launched.

The IMS Health Drug Launches database yields reliable estimates of the number of new (post-1981) drugs, but not of the number of old (pre-1982) drugs, or of the total

\footnotetext{
${ }^{5}$ IMS Health Drug Launches is now known as IMS Lifecyle New Product Focus.

${ }^{6}$ A drug can be associated with more than one therapeutic area. For example, 6 products containing cefmenoxime were classified as infectious/parasitic disease drugs, and 5 products containing cefmenoxime were classified as sensory organ drugs.
} 
$($ new + old $)$ number of drugs. This is due to the fact that the launch data are rightcensored: the IMS Health Drug Launches database does not cover products that were launched before 1982. Suppose that products launched in a country before 1982 contained a certain ingredient, but that no products launched since 1982 did. Provided that the products launched before 1982 are still on the market, that ingredient is still available to consumers, but we would not count it as an available ingredient. We can accurately measure the number of new drugs since, if an ingredient is identified by IMS as a new chemical entity, it could not have been launched prior to the initial launch date provided in the database.

If an ingredient is designated an NCE, then we can be confident that the date of the earliest observed launch of that ingredient in that country is the initial launch date. However, if an ingredient is not designated an NCE, then the date of the earliest observed launch of that ingredient in that country may not be the initial launch date-the ingredient may have been launched in that country prior to $1982 .^{7}$ In other words, NCE launches are guaranteed to be initial launches, but non-NCE launches may be either initial launches or re-launches; we suspect they are predominantly the latter.

To address the censoring problem, we will estimate two different models:

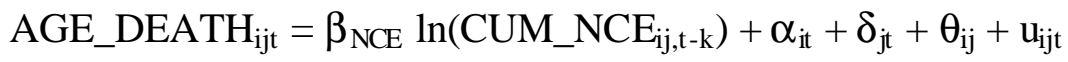

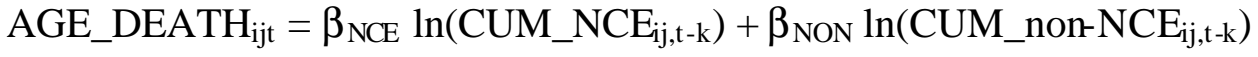

where

$$
+\alpha_{i t}+\delta_{j t}+\theta_{i j}+u_{i j t}
$$

CUM_NCE $=$ the cumulative number of NCEs launched

CUM_non-NCE $=$ the cumulative number of non-NCEs launched

In eq. (4a), AGE_DEATH depends only on the cumulative number of NCEs launched, whereas in eq. (4b), it depends on both the cumulative number of NCEs launched and the cumulative number of non-NCEs launched. We hypothesize that $\beta_{\mathrm{NCE}}$

\footnotetext{
${ }^{7}$ Numerous products containing the same ingredient may be launched (e.g. by branded and generic firms) in a given country.
} 
$>\beta_{\text {NON }}$, i.e. that increases in the stock of NCEs increase AGE_DEATH more than increases in the stock of NCEs. While one might expect $\beta_{\text {NON }}$ to be positive, or at least nonnegative, we can think of a reason why $\beta_{\text {NON }}$ might be negative. Our basic hypothesis is that the greater the proportion of people consuming NCEs, the higher mean age at death will be. It is plausible that the proportion of people consuming NCEs is positively related to the number of NCEs launched and negatively related to the number of nonNCEs launched. Suppose, for example, that $\beta_{N O N}=-\beta_{N C E}$; then eq. ( $4 b$ ) reduces to

$$
\begin{array}{r}
A G E \_D E A T H \\
i j t= \\
\beta_{N C E} \ln \left(C U M \_N C E_{i j, t-k} / C U M \_n o n-N C E_{i j, t-k}\right) \\
+\alpha_{i t}+\delta_{j t}+\theta_{i j}+u_{i j t}
\end{array}
$$

AGE_DEATH depends on the ratio of NCEs to non-NCEs approved. The higher this ratio, the higher the probability that a person is consuming an NCE, as opposed to a nonNCE drug.

\section{Age distribution of deaths}

We obtained data on the age distribution of deaths, by disease, country, and year, from the World Health Organization (WHO) Mortality Database. ${ }^{8}$ These data enable us to compute the fraction of deaths that occur above (or probability of survival until) certain ages, such as 55 and 65 years of age.

We wish to provide estimates of the impact of new drug launches on life expectancy (at various ages, and for the population overall), as well as on survival probabilities. While complete life tables (which include life expectancies and survival probabilities) are available at the country level for various years, there are no diseasespecific life tables, e.g. there are no published data on life expectancy of people with heart disease. However, we believe we can use aggregate life tables to translate our estimates of the impact of new drug launches on survival probabilities into estimates of the impact of new drug launches on life expectancy.

We obtained two different samples of country-level life tables: a time-series of decennial life tables for the U.S. for the period 1900-2000, and a cross-section of life

\footnotetext{
${ }^{8}$ http://www3.who.int/whosis/whsa/ftp/download.htm
} 
tables for 191 countries in the year 2000. Each life table contains the following variables: life expectancy (years of remaining life) at age a $\left(\mathrm{LE}_{\mathrm{a}}, \mathrm{a}=0,5,10, \ldots, 100\right)$, and the probability of survival from birth until age 65 (SURV65). The data suggest that SURV65 is a fairly good "sufficient statistic" for characterizing changes or differences in life expectancy. This is illustrated by Figure 3, which graphs life expectancy at two different ages (birth and age 30) against SURV65, using data from the 11 decennial U.S. life tables during the period 1900-2000. The $\mathrm{R}^{2}$ of the regression of life expectancy at age 30 ( $\mathrm{LE}_{30}$ ) on SURV65 is .974, and the slope is 30.9 , indicating that a .01 increase in SURV65 is associated with a 0.31-year increase in $\mathrm{LE}_{30}$. The $\mathrm{R}^{2}$ of the regression of life expectancy at birth ( $\left.\mathrm{LE}_{0}\right)$ on SURV65 is even higher (.997), and the slope is 66.0, indicating that a .01 increase in SURV65 is associated with a 0.66-year increase in LE $_{0}$.

We computed the regressions of life expectancy at each age $\left(\mathrm{LE}_{\mathrm{a}}, \mathrm{a}=0,5,10, \ldots\right.$, 100) on SURV65, using both the time-series U.S. sample of life tables, and the crosssectional international sample. The regression coefficients are plotted in Figure 4. The estimates yielded by the two samples are fairly consistent with one another. For example, the slopes of the age-0 U.S. and international regressions are 66.0 and 60.3, respectively, and the slopes of the age-30 regressions are 30.9 and 34.3, respectively.

Suppose that we estimate eq. (4a), where AGE_DEATH $\mathrm{ijt}_{\mathrm{i}}$ is defined as PCT_GT65 $5_{\mathrm{ijt}}$ - the percent of deaths from disease $\mathrm{i}$ in country $\mathrm{j}$ in year $\mathrm{t}$ that occurred above the age of 65. PCT_GT65 is presumably a reasonable estimate of SURV65. Hence $\beta_{\mathrm{NCE}} \approx \delta \mathrm{SURV} 65 / \delta \ln \left(\mathrm{CUM} \_\right.$NCE). To estimate $\delta \mathrm{LE}_{\mathrm{a}} / \delta \ln \left(\mathrm{CUM} \_\right.$NCE), we simply multiply $\beta_{\mathrm{NCE}}$ by the regression coefficient shown in Figure 4. For example, using the U.S. estimate, $\delta \mathrm{LE}_{0} / \delta \ln \left(\mathrm{CUM} \_\mathrm{NCE}\right)=66.0 * \beta_{\mathrm{NCE}}$.

In addition to estimating the impact of new drug launches on life expectancy at given ages, we can estimate the impact on the overall life expectancy of the population( $\left.\mathrm{LE}_{\mathrm{POP}}\right),{ }^{9}$ by calculating the weighted average of the regression coefficients shown in Figure 4, weighting by the share of the population in each age group. The resulting life-expectancy multipliers are as follows: ${ }^{10}$

\footnotetext{
${ }^{9} \mathrm{LE}_{\mathrm{POP}}=\left(\Sigma_{\mathrm{a}} \mathrm{w}_{\mathrm{a}} \mathrm{LE}_{\mathrm{a}}\right)$, where $\mathrm{w}_{\mathrm{a}}$ is the share of the population in age group a.

${ }^{10}$ We used the age distribution of the U.S. in 1995 to construct the U.S. figure, and the age distribution of the world in 1995 to construct the international figure.
} 


\begin{tabular}{|l|c|}
\hline & $\delta$ LEPOP $/ \delta \ln ($ CUM_NCE $)$ \\
\hline U.S. time series, $1900-2000$ & $30.8 * \beta_{\mathrm{NCE}}$ \\
\hline international cross section, 2000 & $35.1 * \beta_{\mathrm{NCE}}$ \\
\hline mean & $33.0 * \beta_{\mathrm{NCE}}$ \\
\hline
\end{tabular}

To convert an estimate of the effect of a change in $\ln$ (CUM_NCE) on SURV65 to an estimate of its effect on life expectancy of the overall population, simply multiply by 33 !

\section{Linkage of drug launches to diseases}

The drug launches documented in the IMS Health Drug Launches database are classified by therapeutic category. The classification system used by IMS is very detailed, but hierarchical. At the lowest (most detailed) level, there are more than 500 therapeutic classifications, e.g. prostaglandin antiulcerants (A2B3), and ACE inhibitor combinations with calcium antagonists (C9B3). At the highest level, there are 16 categories, e.g. Alimentary Tract And Metabolism (A), and Cardiovascular System (C).

The deaths documented in the WHO Mortality Database are classified by cause (disease), using the International Classification of Diseases (ICD). ${ }^{11}$ Like the drug classification system, the ICD is very detailed, but hierarchical. At the highest level, there are 17 disease categories, e.g. Neoplasms (ICD10 codes C00-D48) and Diseases of the circulatory system (I00-I99).

The high-level IMS drug classification corresponds quite closely to the high-level ICD disease classification. ${ }^{12}$ For example, cardiovascular system drugs obviously correspond to (are used to treat) diseases of the circulatory system. We defined 11 broad disease categories, and classified drug launches and deaths into these categories as follows:

\footnotetext{
${ }^{11}$ From 1982 to 1993, all deaths were classified using the ninth revision of the ICD (ICD9). In 1994, some countries began to report mortality data using the tenth revision of the ICD (ICD10). By 2001, most countries reported mortality data using the ICD10.

${ }^{12}$ Establishing a correspondence between the two classifications at a more detailed level is far more difficult.
} 


\begin{tabular}{|l|l|l|}
\hline IMS drug class(es) & ICD10 codes & ICD10 disease class(es) \\
\hline $\begin{array}{l}\text { A Alimentary Tract And } \\
\text { Metabolism }\end{array}$ & $\begin{array}{l}\text { K00-K92, } \\
\text { E00-E88 }\end{array}$ & $\begin{array}{l}\text { Diseases of the digestive system; endocrine, } \\
\text { nutritional and metabolic diseases }\end{array}$ \\
\hline $\begin{array}{l}\text { B Blood and Blood Forming } \\
\text { Organs }\end{array}$ & D50-D89 & $\begin{array}{l}\text { Diseases of the blood and blood-forming } \\
\text { organs and certain disorders involving the } \\
\text { immune mechanism }\end{array}$ \\
\hline C Cardiovascular System & I00-I99 & Diseases of the circulatory system \\
\hline D Dermatologicals & L00-L98 & Diseases of the skin and subcutaneous tissue \\
\hline $\begin{array}{l}\text { G Genitourinary System and } \\
\text { Sex Hormones }\end{array}$ & N00-N98 & Diseases of the genitourinary system \\
\hline $\begin{array}{l}\text { J General Anti-Infectives, } \\
\text { Systemic; P Parasitology }\end{array}$ & A00-B99 & Certain infectious and parasitic diseases \\
\hline L Cytostatics & C00-D48 & Neoplasms \\
\hline M Musculoskeletal System & M00-M99 & $\begin{array}{l}\text { Diseases of the musculoskeletal system and } \\
\text { connective tissue }\end{array}$ \\
\hline N Central Nervous System & F01-F99, & $\begin{array}{l}\text { Mental and behavioural disorders, diseases of } \\
\text { the nervous system }\end{array}$ \\
\hline GNS) & G00-G98 & Diseases of the respiratory system \\
\hline R Respiratory System & J00-J98 & $\begin{array}{l}\text { Hiseases of the eye and adnexa; diseases of } \\
\text { the ear and mastoid process }\end{array}$ \\
\hline H60-H93 Sensory Organs & &
\end{tabular}

\section{Descriptive statistics}

The IMS Health Drug Launches data indicate that 864 NCEs were introduced worldwide during 1982-2001. Figure 5 shows the number of NCEs introduced in each year. The annual number ranged from 34 to 59 .

Figure 6 shows the distribution of NCEs launched, by principal therapeutic class. The four largest classes account for 54\% of all NCEs launched. As shown in Figure 7, the distribution of deaths, by cause (each cause corresponds to a therapeutic class), is much more skewed. One cause - circulatory diseases—accounts for almost half (48\%) of all deaths. The next three largest causes are neoplasms (27\%), respiratory diseases (10\%), and digestive/endocrine/nutritional/metabolic diseases (8\%). The four largest causes account for $93 \%$ of deaths.

Table 1 shows the number of NCEs launched, by country, for countries covered in the database from 1982 to at least 2001. The three countries with the largest number of NCE launches (over 400) were Italy, Japan, and the U.S. Even in these countries, fewer 
than half of NCEs launched worldwide were launched. In six of the 40 countriesMalaysia, Egypt, Saudi Arabia, Singapore, Pakistan, and Indonesia-fewer than 200 NCEs were launched.

Table 2 shows the number of deaths, and the percent of deaths at age greater than or equal to 65 , by country, in the most recent year for which mortality data for that country were available.

\section{Empirical results}

Estimates of eqs. (4a) and (4b) are shown in Table 3. The dependent variable in all equations is the fraction of deaths that occurred at age 65 and over. ${ }^{13}$ All equations were estimated using data on 11 diseases in 52 countries over a maximum of 20 years (1982-2001). All equations included complete sets of country*year, disease*year, and country*disease interaction effects. For example, the zero-lag equation $(\mathrm{k}=0)$, which was estimated using 4678 observations, included 496 country*year effects, 189 disease*year effects, and 502 country*disease effects. The equations were estimated via weighted least squares, using the number of deaths in that disease-country-year cell as the weight.

The first column of Table 3 shows the regression of AGE_DEATH $\mathrm{ijt}_{\mathrm{t}}$ on $\ln \left(\mathrm{CUM}_{-} \mathrm{NCE}_{\mathrm{ijt}}\right)$, i.e. a regression on the contemporaneous stock of NCEs, without controlling for the stock of non-NCEs. The estimate of $\beta_{\mathrm{NCE}}$ is positive and statistically significant, which is consistent with the hypothesis that NCE launches increase longevity. The second column of the table shows the regression of AGE_DEATH $\mathrm{ijt}_{\mathrm{ijt}}$ on both $\ln \left(\mathrm{CUM} \_N C E_{\mathrm{ijt}}\right)$ and $\ln \left(\mathrm{CUM}\right.$ _non-NCE $\left.\mathrm{ijt}_{\mathrm{jt}}\right)$. Controlling for the stock of non-NCEs has very little impact on the estimate of $\beta_{\mathrm{NCE}}$. The estimate of $\beta_{\mathrm{NON}}$ is negative and marginally significant, suggesting that, conditional on the cumulative number of NCE launches, the greater the cumulative number of non-NCE launches, the lower the probability of survival to age 65 . This is consistent with the view that increasing the ratio

\footnotetext{
${ }^{13}$ We also estimated models using the log-odds of survival until age 65, i.e. $\log (\mathrm{PCT}$ _GT65/(1 PCT_GT65)), and using a different age thre shold (55 instead of 65). The results were qualitatively similar to those reported in the text.
} 
of non-NCE to NCE launches reduces the fraction of people consuming NCEs, which in turn reduces longevity. The difference $\left(\beta_{\mathrm{NCE}}-\beta_{\mathrm{NON}}\right)$ is positive and significant.

The remaining columns of Table 3 present regressions that are similar, except the regressors are lagged, rather than contemporaneous, values of the stocks of NCEs and non-NCEs. The third column of Table 3 shows the regression of AGE_DEATH $\mathrm{ijt}_{\mathrm{i}}$ on $\ln \left(\mathrm{CUM} \_\mathrm{NCE}_{\mathrm{ij}, \mathrm{t}-1}\right)$, i.e. a regression on the stock of NCEs in the previous year, without controlling for the stock of non-NCEs. The estimate of $\beta_{\mathrm{NCE}}$ is about $50 \%$ larger than it is in column 1, suggesting that longevity is more closely related to the lagged stock of NCEs than it is to the contemporaneous stock, presumably due to gradual diffusion of NCEs following launch. The fourth column of the table shows the regression of

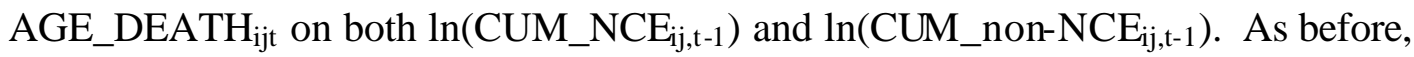
controlling for the stock of non-NCEs has very little impact on the estimate of $\beta_{\mathrm{NCE}}$. The estimate of $\beta_{\text {NON }}$ is also about $50 \%$ larger than it is in column 2 , as is the estimate of the difference $\left(\beta_{\mathrm{NCE}}-\beta_{\mathrm{NON}}\right)$.

The fifth column of Table 3 shows the regression of AGE_DEATH $\mathrm{H}_{\mathrm{ijt}}$ on

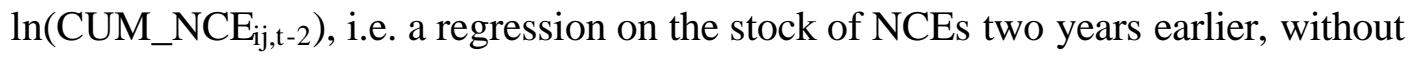
controlling for the stock of non-NCEs. Once again, the estimate (and t-statistic) of $\beta_{\mathrm{NCE}}$ increases by about $50 \%$. The sixth column of the table shows the regression of AGE_DEATH $\mathrm{ijt}_{\mathrm{jt}}$ on both $\ln \left(\mathrm{CUM} \_N C E_{\mathrm{ij}, \mathrm{t}-2}\right)$ and $\ln \left(\mathrm{CUM} \_\right.$non-NCE $\left.\mathrm{i}_{\mathrm{ij}, \mathrm{t}-2}\right)$. The estimate of $\beta_{\mathrm{NON}}$ is slightly smaller, and less significant, than it was in column 4.

The remaining columns of Table 3 show estimates of the model for higher (3- to 6-year) lags between the stock of drugs launched and the age-65 survival probability. The estimate of $\beta_{\mathrm{NON}}$ is not significantly different from zero when the lag is 3 or more years. ${ }^{14}$ As summarized in Figure 8, the estimate of $\beta_{\mathrm{NCE}}$ increases as the lag increases from 0 to 3 years, and then levels off. This suggests that it takes three years for new NCE launches to have their maximum impact on survival rates. We hypothesize that this is due to the gradual diffusion of drugs to consumers following launch.

\footnotetext{
${ }^{14}$ The insignificance of $\beta_{\mathrm{NON}}$ suggests that the launch of generic drugs does not increase longevity. This might seem surprising, since generic launches might be expected to increase access and utilization of drugs. However Berndt, Kyle, and Ling (2003) found that utilization of $\mathrm{H}_{2}$-antagonist drugs by Americans declined following patent expiration; this may be due to the fact that branded firms cut back considerably on marketing efforts beginning several years prior to patent expiration. Moreover, the ratio of generic prices to branded prices may be much higher outside the U.S. than it is in the U.S.
} 
If NCEs diffuse gradually following launch, this might be reflected in pharmaceutical expenditure behavior. An increase in the stock of NCEs is likely to result in an increase in per capita pharmaceutical expenditure, via both increased utilization and higher prices. From the OECD Health Database, we obtained data, by country and year, on per capita pharmaceutical expenditure, expressed in U.S. dollars, evaluated at PPP (Rx_expend). ${ }^{15}$ After linking these data to the IMS Health Drug Launches data, we estimated the following equation for different values of $\mathrm{k}(\mathrm{k}=0,1,2, \ldots, 6)$ :

$$
\ln \left(\text { Rx_expend }_{\mathrm{jt}}\right)=\beta_{\text {expend }} \ln \left(\mathrm{CUM} \mathrm{NCE}_{\mathrm{j}, \mathrm{t}-\mathrm{k}}\right)+\delta_{\mathrm{t}}+\theta_{\mathrm{j}}+\mathrm{u}_{\mathrm{jt}}
$$

The estimates are shown in the following table.

\begin{tabular}{|l|c|c|c|c|c|c|c|}
\hline lag & 0 & 1 & 2 & 3 & 4 & 5 & 6 \\
\hline & & & & & & & \\
\hline$\beta_{\text {expend }}$ & -0.0087 & 0.0024 & 0.0145 & 0.0325 & 0.0421 & 0.0431 & 0.0400 \\
\hline s.e. & 0.0132 & 0.0134 & 0.0135 & 0.0140 & 0.0161 & 0.0189 & 0.0230 \\
\hline t-stat & -0.66 & 0.18 & 1.07 & 2.32 & 2.61 & 2.28 & 1.73 \\
\hline p-value & 0.5104 & 0.861 & 0.2849 & 0.0211 & 0.0097 & 0.0239 & 0.0848 \\
\hline
\end{tabular}

For $\mathrm{k} \leq 2, \beta_{\text {expend }}$ is not significantly different from zero. This suggests that increases in the stock of NCEs have no impact on per capita pharmaceutical expenditure within two years. However, for $3 \leq \mathrm{k} \leq 5, \beta_{\text {expend }}$ is positive and statistically significant: increases in the stock of NCEs increase per capita pharmaceutical expenditure after three years. These results seem consistent with the time profile of the estimated effect of $\beta_{\mathrm{NCE}}$ (the impact of the NCE stock on survival probability). Estimates of $\beta_{\mathrm{NCE}}$ and $\beta_{\text {expend }}$ at different lag values are plotted in Figure 9. It takes three to five years for an increase in the stock of NCEs to have its full impact on both pharmaceutical expenditure and survival rates.

\section{Implications of the estimates}

Our estimates can be used to provide answers to several important questions:

\footnotetext{
${ }^{15}$ Unfortunately, these data are not available by disease, and are only available for OECD countries.
} 
- How much of the cross-country variation in longevity in a given year (e.g. 2000) is explained by international variation in the stock of NCEs launched since 1982?

- How much of the long-run increase in longevity in the sample as a whole is due to the launch of NCEs?

- What is the cost per life-year gained from the launch of NCEs?

To answer these questions, we will use the estimate of $\beta_{\mathrm{NCE}}$ from column 9 of Table 3 , i.e. we will assume that $\left(\Delta \mathrm{PCT} \_\mathrm{GT} 65_{\mathrm{ijt}} / \Delta \ln \left(\mathrm{CUM} \_\mathrm{NCE}_{\mathrm{ij}, \mathrm{t}-4}\right)\right)=.0065$. Recall that this estimate controls for all other factors affecting PCT_GT65 that are invariant across diseases within a country and year, invariant across countries within a disease and year, or invariant across years within a country and disease. Also, as argued above, the effect of NCE launches on life expectancy at birth $\left(\mathrm{LE}_{0}\right)$ can be approximated by $(63.2 * .0065)$ $=0.4105$, and the effect of NCE launches on average life expectancy of the entire population $\left(\mathrm{LE}_{\mathrm{POP}}\right)$ can be approximated by $(33.0 * .0065)=.2145$.

\section{Cross-sectional differences}

Heterogeneity with respect to NCE launches appears to explains very little of the international variation in longevity. ${ }^{16}$ As shown in Table 1, the countries with the highest and lowest number of NCE launches during the period 1982-2001 were Italy (422 NCE launches) and Malaysia (122 NCE launches), respectively. According to our estimates, the predicted difference in life expectancy at birth resulting from this launch differential is $\Delta \mathrm{LE}_{0}=0.4105 * \Delta \ln \left(\mathrm{CUM} \_\mathrm{NCE}\right)=0.4105 * \ln (422 / 122)=.51$ years. This is only $9 \%$ of the difference between life expectancy at birth in Italy (78.7) and Malaysia (73.0) in 2000-2005. ${ }^{17}$

\footnotetext{
${ }^{16}$ Sample selection bias could conceivably lead us to underestimate the role of NCE launches in international longevity variation. WHO monitors mortality in 191 countries; IMS monitors drug launches in only 72 countries. Perhaps the number of NCEs launched in countries not monitored by IMS tends to be much lower than the number of NCEs launched in countries monitored by IMS.

${ }^{17}$ As reported in the United Nations World Population Prospects Database.
} 


\section{Time-series differences}

In contrast, NCE launches appear to account for a significant fraction of the longrun increase in longevity in the sample as a whole. To measure this contribution, we adopted the following procedure. First, we inferred the average growth of PCT_GT65 from estimates of the year effects $\left(\delta_{t}\right.$ s $\left.s\right)$ from the following equation:

$$
\text { PCT_GT65 } 5_{\mathrm{ijt}}=\delta_{\mathrm{t}}+\theta_{\mathrm{ij}}+\mathrm{u}_{\mathrm{ijt}}
$$

$\left(\delta_{t}-\delta_{1986}\right)$ is an estimate of the change in the survival rate (and $33.0 *\left(\delta_{t}-\delta_{1986}\right)$ is an estimate of the change in $\left.\mathrm{LE}_{\mathrm{POP}}\right)$ between 1986 and year $\mathrm{t}(\mathrm{t}=1987,1988, \ldots, 2000)$, controlling for country*disease effects. Second, we inferred the average rate of growth of CUM_NCE from estimates of the year effects $\left(\lambda_{t}{ }^{6} s\right)$ from the following equation ${ }^{18}$ :

$$
\ln \left(C U M \_N C E_{i j t}\right)=\lambda_{t}+\psi_{i j}+v_{i j t}
$$

$\left(\lambda_{t}-\lambda_{1986}\right)$ is an estimate of the change in the log of the stock of NCEs between 1986 and year $t$, controlling for country*disease effects. Finally, the contribution of NCE launches to the increase in survival rates between 1986 and year $t$ is equal to $\left(.0065^{*}\left(\lambda_{t}-\lambda_{1986}\right)\right)$, and the contribution of NCE launches to the increase in LEPOP is equal to $(33.0 * .0065 *$ $\left.\left(\lambda_{t}-\lambda_{1986}\right)\right)$.

These calculations are summarized in Figure 10. Between 1986 and 2000, average life expectancy of the entire population increased by almost two (1.96) years. (The fraction of deaths that occurred at or above age 65 increased by 6 percentage points.) Our estimates imply that NCE launches accounted for 0.79 years (40\%) of the 1986-2000 increase in longevity. The average annual increase in life expectancy of the entire population resulting from NCE launches is .056 years $(=0.79$ / 14), or 2.93 weeks.

These results suggest that launch delays reduce longevity. Suppose that drugs tend to be launched much later in country B than they are in country A, so that country B's stock of drugs today is the same as country A's stock 5 years ago. The estimates

\footnotetext{
${ }^{18}$ Both this and the previous equation were estimated via weighted least squares, weighting by the number of deaths in that disease-country-year cell.
} 
imply that this launch delay reduces the average longevity of the entire population in country B by about 15 weeks. Danzon, Wang and Wang (2002) present evidence that countries with lower prices or smaller market size experience longer delays in access to new drugs.

Cost per life-year gained from the launch of NCEs

The cost per life-year gained from the launch of NCEs appears to be extremely low. OECD data indicate that in 1997, average per capita pharmaceutical expenditure in OECD countries was about $\$ 250$. The average annual increase in life expectancy of the entire population resulting from NCE launches is .056 years. The ratio of these two numbers - pharmaceutical expenditure per person per year divided by the increase in lifeyears per person per year attributable to NCE launches—is about $\$ 4500$. This is far lower than most estimates of the value of a life-year (Nordhaus (2002), Murphy and Topel (2003)). Moreover, since the numerator includes expenditure on old drugs as well as on recently-launched NCEs, it probably grossly overstates the cost per life-year gained from the launch of NCEs.

\section{Summary}

Until recently, there appears to have been a consensus among health economists (or at least authors of health economics textbooks) that the contribution of medical care to longevity increase and other health improvements has been quite modest. But some recent research has indicated that technological innovations in medicine have had important positive impacts on health.

In this paper, we have performed an econometric analysis of the effect of new drug launches on longevity. Drugs are much more research-intensive than most other goods and services utilized in the health care sector, so new drug introductions account for a substantial fraction of medical innovations.

Our sample included data on virtually all of the diseases borne by people in 52 countries during the period 1982-2001. Analysis of the relationship between new drug launches and longevity using these data enabled us to control, to an unusually great 
extent, for the effects of other potential determinants of longevity, e.g. education, income, nutrition, the environment, and "lifestyle".

We used data from the IMS Health Drug Launches database to construct estimates of the number of drugs launched to treat eleven different diseases in each country in each year. This database has tracked new product introductions worldwide since 1982, and contained over 165,000 records of individual product introductions. We obtained data on the age distribution of deaths, by disease, country, and year, from the World Health Organization (WHO) Mortality Database. These data enabled us to compute the fraction of deaths that occur above (or probability of survival until) certain ages, such as 55 and 65 years of age.

We found that launches of New Chemical Entities (NCEs) have a strong positive impact on the probability of survival. The estimates indicated that it takes at least three years for new NCE launches to have their maximum impact on survival rates. This is probably due to the gradual diffusion of drugs to consumers following launch; data on pharmaceutical expenditure were consistent with this interpretation.

Launches of (older) drugs that are not NCEs - many of which may already have been on the market-do not increase longevity. Indeed, some estimates indicated that, conditional on the cumulative number of NCE launches, the greater the cumulative number of non-NCE launches, the lower the probability of survival to age 65. This is consistent with the view that increasing the ratio of non-NCE to NCE launches reduces the fraction of people consuming NCEs, which in turn reduces longevity.

Heterogeneity with respect to NCE launches appears to explains very little of the international variation in longevity. But NCE launches appear to account for a significant fraction of the long-run increase in longevity in the sample as a whole. Between 1986 and 2000, average life expectancy of the entire population of sample countries increased by almost two (1.96) years. Our estimates imply that NCE launches accounted for 0.79 years (40\%) of the 1986-2000 increase in longevity. The average annual increase in life expectancy of the entire population resulting from NCE launches is .056 years, or 2.93 weeks. 
Previous authors have shown that countries with lower prices or smaller market size experience longer delays in access to new drugs; our results imply that launch delays reduce longevity.

The cost per life-year gained from the launch of NCEs appears to be extremely low. Pharmaceutical expenditure per person per year divided by the increase in life-years per person per year attributable to NCE launches is about $\$ 4500-$-far lower than most estimates of the value of a life-year. Moreover, since the numerator includes expenditure on old drugs as well as on recently-launched NCEs, it probably grossly overstates the cost per life-year gained from the launch of NCEs. 


\section{References}

Agency for Healthcare Research and Quality (2002), "MEPS H38 Codebook: 1999 Full Year Consolidated Data File Codebook," November 27, http://www.meps.ahrq.gov/Pubdoc/HC038/H38CB.pdf

Arias E. (2002), “United States life tables, 2000," National Vital Statistics Reports 51 (3) (Hyattsville, MD: National Center for Health Statistics).

Berndt, Ernst, Margaret K. Kyle, and Davina Ling (2003), "The long shadow of patent expiration: Do Rx to OTC switches provide an afterlife?," in Scanner Data and Price Indexes, ed. by Robert C. Feenstra and Matthew D. Shapiro (Chicago: University of Chicago Press)

Bresnahan, Timothy, and Robert Gordon (1997), The Economics of New Goods (Chicago: University of Chicago Press).

Cutler, David, and Mark McClellan, "Is technological change in medicine worth it?," Health Affairs 20 (5), September-October 2001, pp. 11-29.

Danzon Patricia, Y. Richard Wang, and Liang Wang (2003), “The Impact of Price Regulation on the Launch Delay of New Drugs - A Study of Twenty-Five Major Markets in the 1990s," http://hc.wharton.upenn.edu/danzon/PDF Files/LaunchDelayPaper.pdf.

Folland, Sherman, Allen Goodman, and Miron Stano (2001), The Economics of Health and Health Care, third edition (Upper Saddle River, NJ: Prentice Hall).

Getzen, Thomas (1997), Health Economics: Fundamentals and Flow of Funds (New York, NY: John Wiley and Sons).

Grier, Holcombe, et al (2003), “Addition of Ifosfamide and Etoposide to Standard Chemotherapy for Ewing's Sarcoma and Primitive Neuroectodermal Tumor of Bone," New England Journal of Medicine 348 (8), pp. 694-701, February 20.

Henderson, James (1999), Health Economics and Policy (Cincinnati, OH: South-Western Publishing Co.).

IMS Health, http://www.ims-global.com/.

Kyle, Margaret K. (2003), "Product Entry in Global Pharmaceutical Markets: A CrossNational Study," unpublished paper, Carnegie-Mellon University.

Lichtenberg, Frank (1996), "Do (More and Better) Drugs Keep People Out of Hospitals?," American Economic Review 86, May, 1996, 384-8. (2001), "Are the Benefits of Newer Drugs Worth Their Cost?

Evidence from the 1996 MEPS," Health Affairs 20(5), September/October, 241-51. 
Murphy, Kevin M., and Robert H. Topel (2003) "The Economic Value of Medical Research," in Measuring the Gains from Medical Research: An Economic Approach, edited by Kevin M. Murphy and Robert H. Topel (Chicago: University of Chicago Press).

Nordhaus, William (2002) "The Health of Nations: The Contribution of Improved Health to Living Standards," NBER Working Paper No. 8818, February.

OECD Health Database, http://www.credes.fr/english/ecosante/oecd.htm.

Romer, Paul (1990), "Endogenous technical change," Journal of Political Economy 98, S71-S102.

Santerre, Rexford, and Stephen Neun (2000), Health Economics: Theories, Insights, and Industry Studies, revised edition (Orlando, FL: Dryden Press).

Stenestrand, U., et al (2001), "Early statin treatment following acute myocardial infarction and 1-year survival," Journal of the American Medical Association 285(4), pp. 430-6, Jan. 24-31.

United Nations, World Population Prospects Population Database, http://esa.un.org/unpp/index.asp?panel=2.

U.S. Pharmacist (2002), "Cancer News," Vol. 27(11), posted November 15, http://www.uspharmacist.com/index.asp?show=article\&page=8_999.htm

World Health Organization, WHO Mortality Database, http://www3.who.int/whosis/whsa/ftp/download.htm. 
Table 1

Table 1

Number of NCEs and non-NCEs launched, by country

\begin{tabular}{|c|c|c|}
\hline Country & $\begin{array}{c}\text { Number of NCEs } \\
\text { launched }\end{array}$ & Number of non-NCEs launched \\
\hline ITALY & 422 & 942 \\
\hline J APAN & 422 & 1193 \\
\hline USA & 414 & 1000 \\
\hline ARGENTINA & 373 & 1676 \\
\hline UK & 373 & 604 \\
\hline AUSTRIA & 350 & 699 \\
\hline SWITZERLAND & 337 & 904 \\
\hline FINLAND & 335 & 396 \\
\hline DENMARK & 333 & 515 \\
\hline MEXICO & 323 & 922 \\
\hline NETHERLANDS & 310 & 448 \\
\hline SWEDEN & 308 & 443 \\
\hline SPAIN & 306 & 693 \\
\hline CANADA & 299 & 990 \\
\hline IRELAND & 292 & 478 \\
\hline FRANCE & 290 & 766 \\
\hline BRAZIL & 283 & 934 \\
\hline BELGIUM & 282 & 533 \\
\hline GREECE & 279 & 575 \\
\hline COLOMBIA & 278 & 852 \\
\hline PHILIPPINES & 277 & 555 \\
\hline THAILAND & 272 & 911 \\
\hline CHILE & 259 & 1032 \\
\hline TURKEY & 241 & 754 \\
\hline SOUTH AFRICA & 234 & 582 \\
\hline NEW ZEALAND & 228 & 728 \\
\hline PORTUGAL & 223 & 499 \\
\hline ECUADOR & 220 & 750 \\
\hline ISRAEL & 219 & 574 \\
\hline PERU & 219 & 1026 \\
\hline VENEZUELA & 215 & 647 \\
\hline HONG KONG & 214 & 415 \\
\hline AUSTRALIA & 213 & 682 \\
\hline INDONESIA & 191 & 773 \\
\hline PAKISTAN & 174 & 1089 \\
\hline SINGAPORE & 171 & 229 \\
\hline SAUDI ARABIA & 153 & 555 \\
\hline EGYPT & 142 & 1037 \\
\hline MALAYSIA & 122 & 249 \\
\hline
\end{tabular}

Source: IMS Health, Drug Launches 
Table 2

Table 2

Number of deaths and percent of deaths at or above age 65 , by country

\begin{tabular}{|c|c|c|c|}
\hline Country & year & number of deaths & $\%$ of deaths at age GE 65 \\
\hline USA & 1999 & $2,188,558$ & $80 \%$ \\
\hline RUSSIA & 2000 & $1,787,514$ & $65 \%$ \\
\hline JAPAN & 1999 & 875,172 & $81 \%$ \\
\hline GERMANY & 1999 & 786,416 & $82 \%$ \\
\hline UK & 1999 & 589,437 & $85 \%$ \\
\hline ITALY & 1999 & 509,733 & $85 \%$ \\
\hline FRANCE & 1999 & 448,640 & $82 \%$ \\
\hline MEXICO & 2000 & 346,605 & $59 \%$ \\
\hline SPAIN & 1999 & 343,186 & $85 \%$ \\
\hline POLAND & 2000 & 313,275 & $74 \%$ \\
\hline EGYPT & 2000 & 271,402 & $43 \%$ \\
\hline PHILIPPINES & 1996 & 252,034 & $45 \%$ \\
\hline ARGENTINA & 1997 & 224,694 & $71 \%$ \\
\hline CANADA & 1998 & 198,312 & $82 \%$ \\
\hline SOUTH AFRICA & 1996 & 184,197 & $41 \%$ \\
\hline SOUTH KOREA & 2000 & 182,021 & $62 \%$ \\
\hline THAILAND & 1994 & 148,426 & $29 \%$ \\
\hline NETHERLANDS & 1995 & 122,692 & $83 \%$ \\
\hline HUNGARY & 2001 & 121,727 & $72 \%$ \\
\hline AUSTRALIA & 1999 & 117,829 & $83 \%$ \\
\hline COLOMBIA & 1998 & 117,028 & $59 \%$ \\
\hline CZECH REPUBLIC & 2000 & 101,022 & $78 \%$ \\
\hline BULGARIA & 2000 & 99,898 & $77 \%$ \\
\hline BELGIUM & 1996 & 93,679 & $84 \%$ \\
\hline GREECE & 1999 & 88,621 & $84 \%$ \\
\hline SWEDEN & 1999 & 88,061 & $88 \%$ \\
\hline PORTUGAL & 2000 & 86,380 & $82 \%$ \\
\hline VENEZUELA & 2000 & 77,011 & $56 \%$ \\
\hline CHILE & 1999 & 68,566 & $72 \%$ \\
\hline AUSTRIA & 2001 & 67,863 & $83 \%$ \\
\hline PERU & 2000 & 61,086 & $58 \%$ \\
\hline SWITZERLAND & 1999 & 56,582 & $85 \%$ \\
\hline DENMARK & 1998 & 50,695 & $82 \%$ \\
\hline SLOVAK REPUBLIC & 2000 & 48,622 & $75 \%$ \\
\hline FINLAND & 2000 & 44,732 & $82 \%$ \\
\hline NORWAY & 1999 & 40,393 & $87 \%$ \\
\hline ECUADOR & 2000 & 37,794 & $56 \%$ \\
\hline ISRAEL & 1998 & 31,986 & $82 \%$ \\
\hline HONG KONG & 2000 & 30,839 & $79 \%$ \\
\hline IRELAND & 1999 & 30,180 & $83 \%$ \\
\hline MALAYSIA & 1997 & 30,084 & $39 \%$ \\
\hline LATVIA & 2000 & 26,971 & $72 \%$ \\
\hline PUERTO RICO & 1999 & 25,965 & $72 \%$ \\
\hline NEW ZEALAND & 1999 & 25,873 & $81 \%$ \\
\hline URUGUAY & 2000 & 25,627 & $78 \%$ \\
\hline DOMINICAN REPUBLIC & 1998 & 19,450 & $52 \%$ \\
\hline SLOVENIA & 1999 & 16,481 & $77 \%$ \\
\hline SINGAPORE & 2000 & 13,350 & $71 \%$ \\
\hline LUXEMBOURG & 2001 & 3,239 & $82 \%$ \\
\hline KUWAIT & 2000 & 3,040 & $44 \%$ \\
\hline PAKISTAN & 1994 & 1,106 & $28 \%$ \\
\hline
\end{tabular}


Table 3

Estimates of eqs. (4a) and (4b)

\begin{tabular}{|l|c|c|c|c|c|c|c|c|c|c|c|c|c|}
\hline Column & 1 & 2 & 3 & 4 & 5 & 6 & 7 & 8 & 9 & 10 & 11 & 12 & 13 \\
\hline & & & & & & & & & & & & & \\
\hline lag & 0 & 0 & 1 & 1 & 2 & 2 & 3 & 3 & 4 & 4 & 5 & 5 & 6 \\
\hline & & & & & & & & & & & & & \\
\hline $\boldsymbol{\beta}_{\text {NCE }}$ & 0.0025 & 0.0023 & 0.0038 & 0.0036 & 0.0055 & 0.0053 & 0.0066 & 0.0063 & 0.0065 & 0.0062 & 0.0071 & 0.0068 & 0.0067 \\
\hline std. error. & 0.0009 & 0.0009 & 0.0009 & 0.0009 & 0.0009 & 0.0009 & 0.0009 & 0.0010 & 0.0010 & 0.0010 & 0.0010 & 0.0010 & 0.0011 \\
\hline t-statistic & 2.66 & 2.43 & 4.05 & 3.86 & 5.85 & 5.62 & 7.01 & 6.67 & 6.64 & 6.27 & 6.93 & 6.58 & 6.25 \\
\hline & & & & & & & & & & & & & \\
\hline & & & & & & & & & & & & & \\
\hline $\boldsymbol{\beta}_{\text {NON }}$ & & -0.0029 & & -0.0044 & & -0.0040 & & -0.0018 & & -0.0006 & & -0.0010 & \\
\hline std. error. & & 0.0015 & & 0.0015 & & 0.0016 & & 0.0016 & & 0.0017 & & 0.0018 & \\
\hline t-statistic & & -1.9 & & -2.87 & & -2.55 & & -1.09 & & -0.38 & & -0.57 & \\
\hline & & & & & & & & & & & & & \\
\hline & & & & & & & & & & & & & \\
\hline $\boldsymbol{\beta}_{\text {NCE }} \boldsymbol{\beta}_{\text {NON }}$ & & 0.0051 & & 0.0080 & & 0.0093 & & 0.0081 & & 0.0068 & & 0.0078 & \\
\hline std. error. & & 0.0018 & & 0.0018 & & 0.0019 & & 0.0019 & & 0.0020 & & 0.0021 & \\
\hline t-statistic & & 2.83 & & 4.38 & & 5.02 & & 4.29 & & 3.46 & & 3.72 & \\
\hline
\end{tabular}

The dependent variable in all equations is the fraction of deaths that occurred at age 65 and over. All equations were estimated using data on 11 diseases in 52 countries over a maximum of 20 years (1982-2001). All equations included complete sets of country*year, disease*year, and country*disease interaction effects. For example, the zero-lag equation (k= 0), which was estimated using 4678 observations, included 496 country*year effects, 189 disease*year effects, and 502 country*disease effects. The equations were estimated via weighted least squares, using the number of deaths in that diseasecountry-year cell as the weight. 
Figure 1

Life expectancy at birth, world

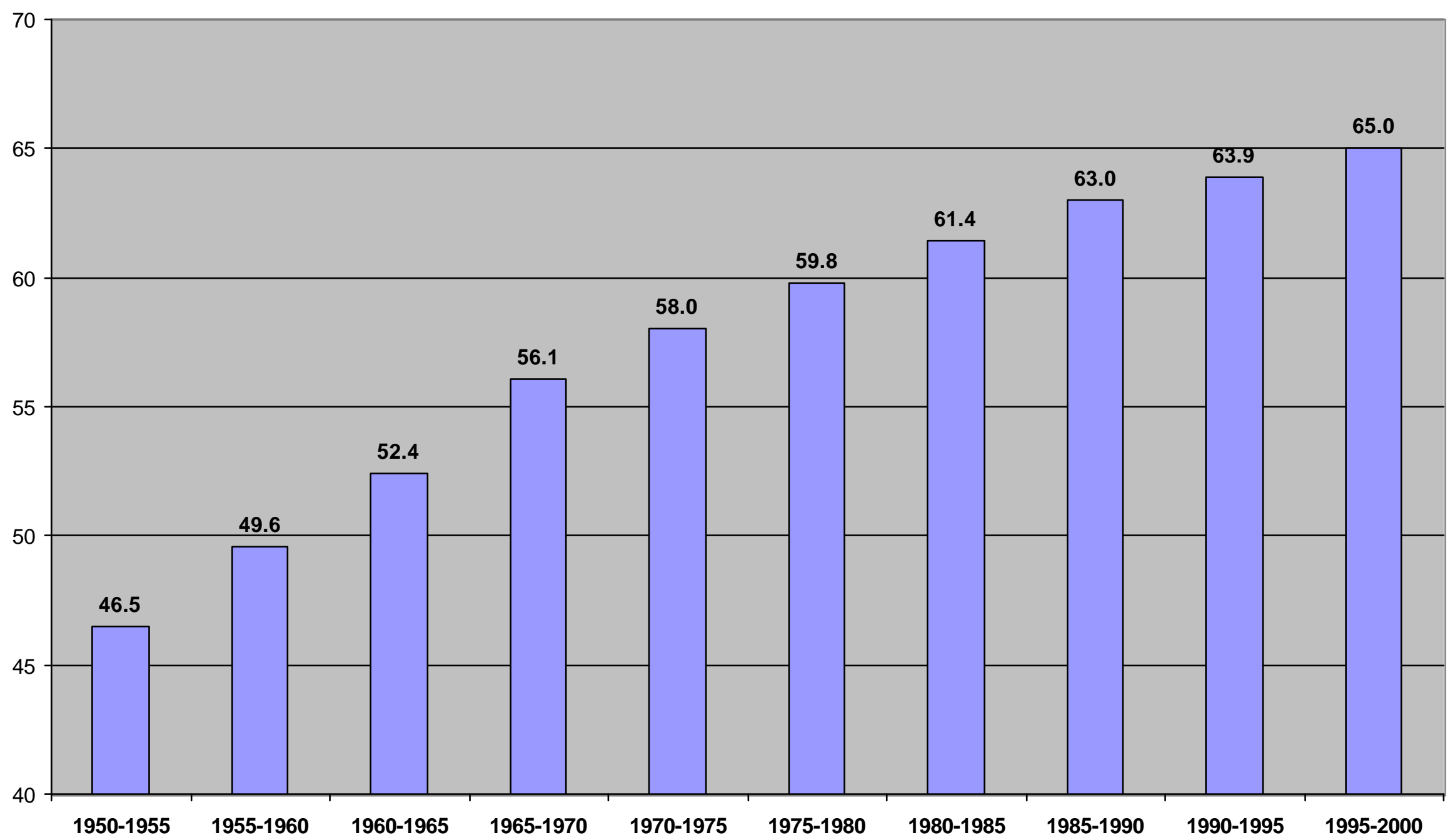


Figure 2

Life expectancy at birth, both sexes, by region

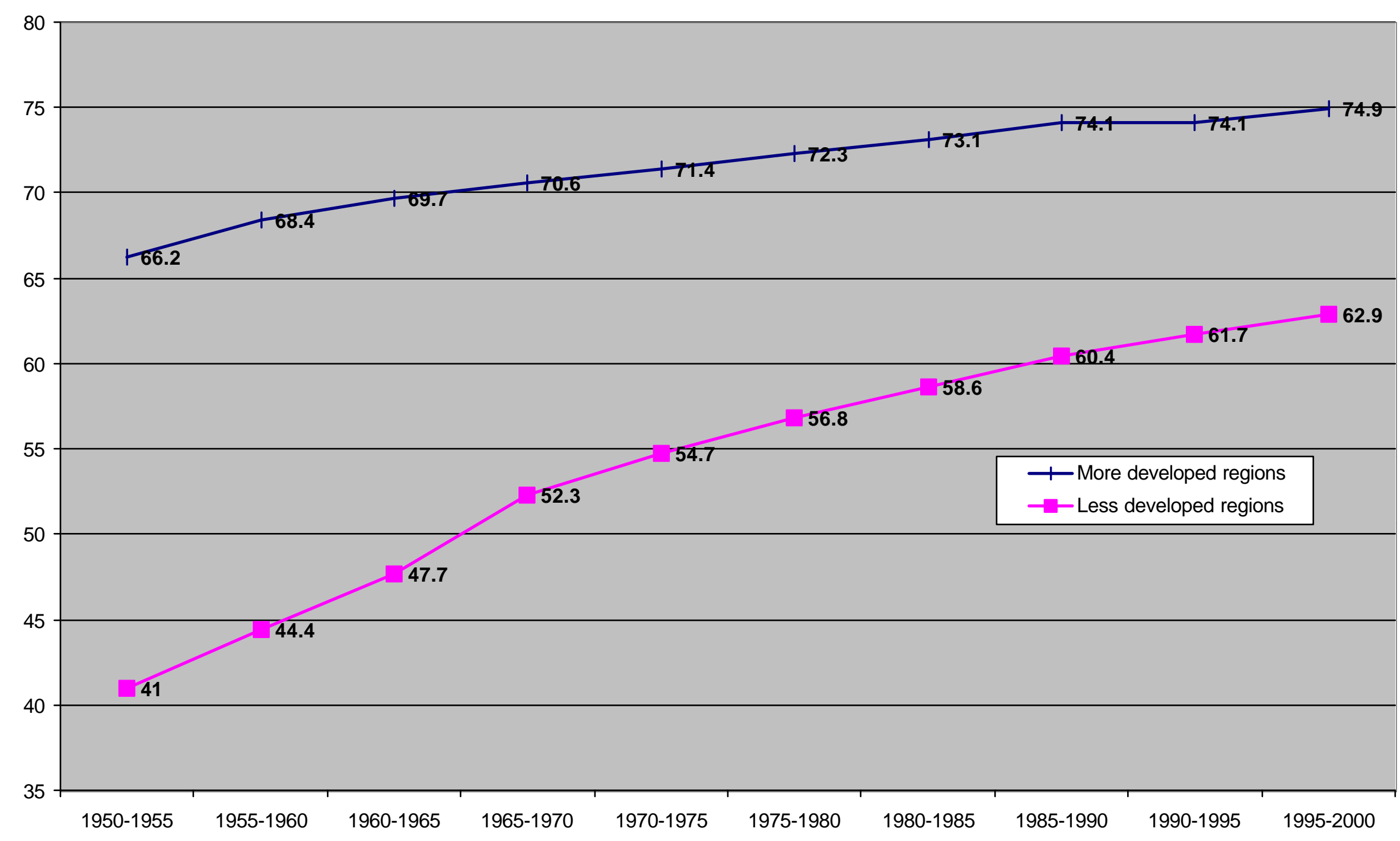


Figure 3

Relationship between life expectancy and probability of survival to age 65

U.S., 1900-2000

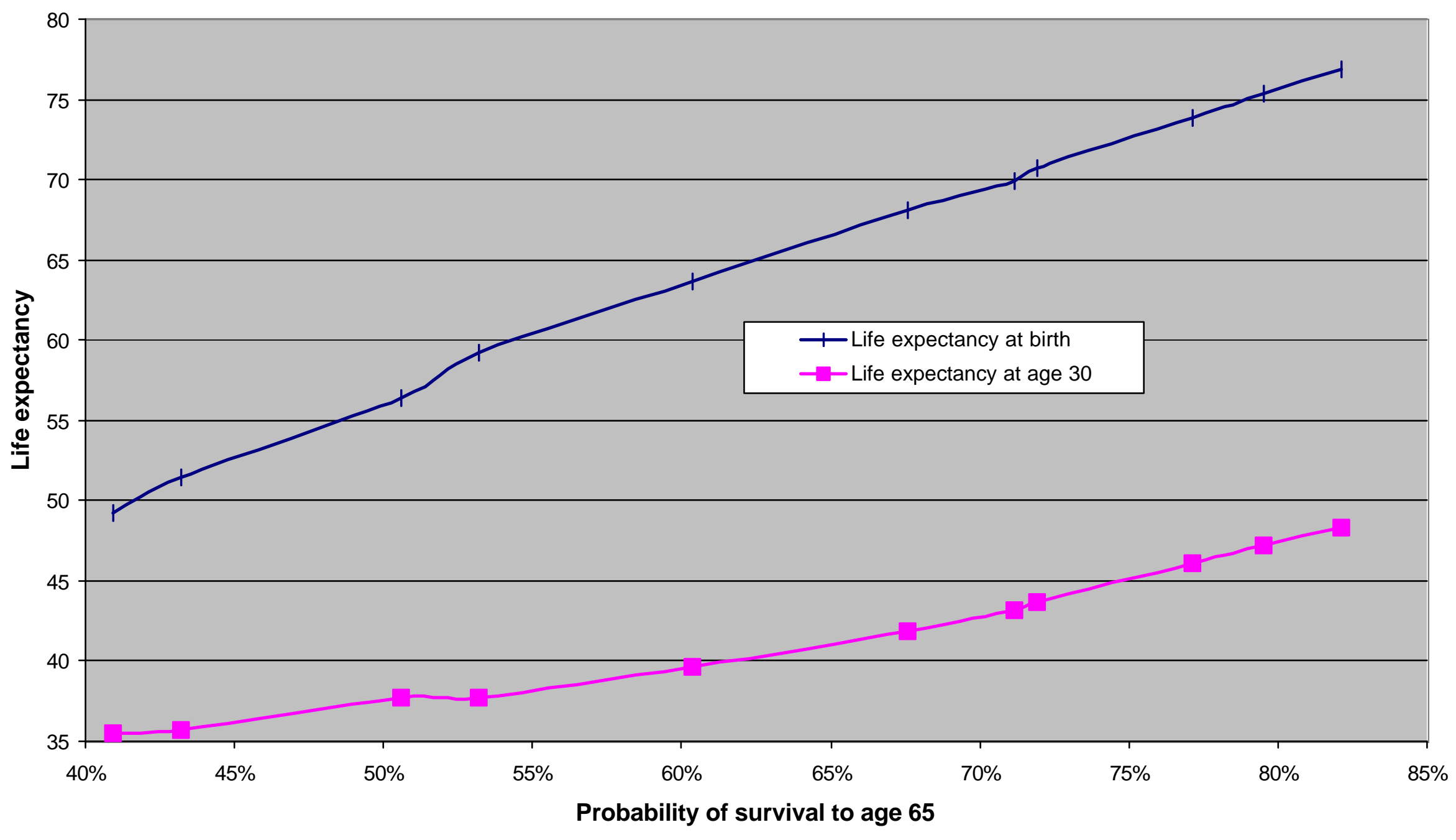


Figure 4

Coefficients from regressions of life expectancy at age a on probability of survival to age 65

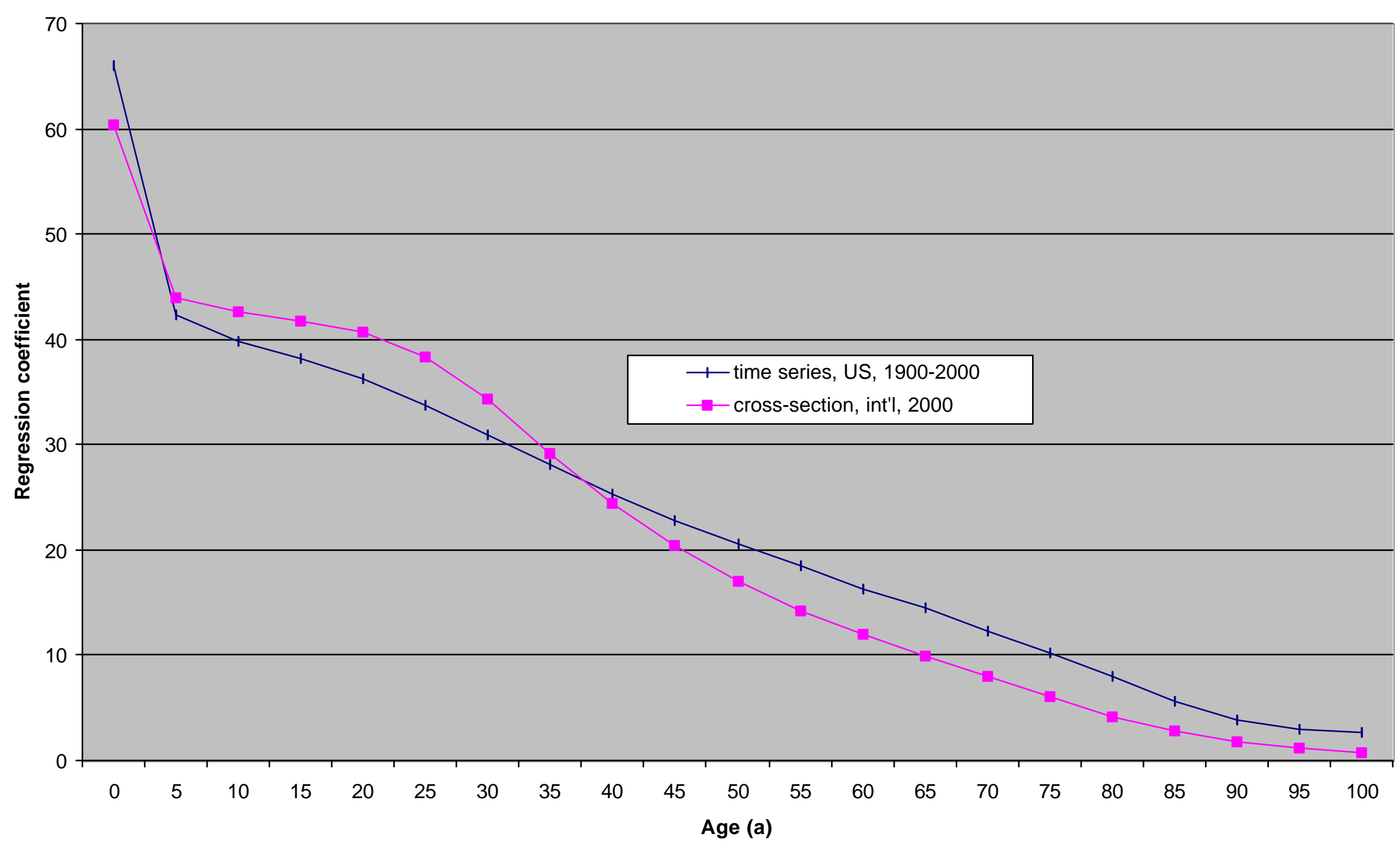


Figure 5

Number of NCEs launched, by year

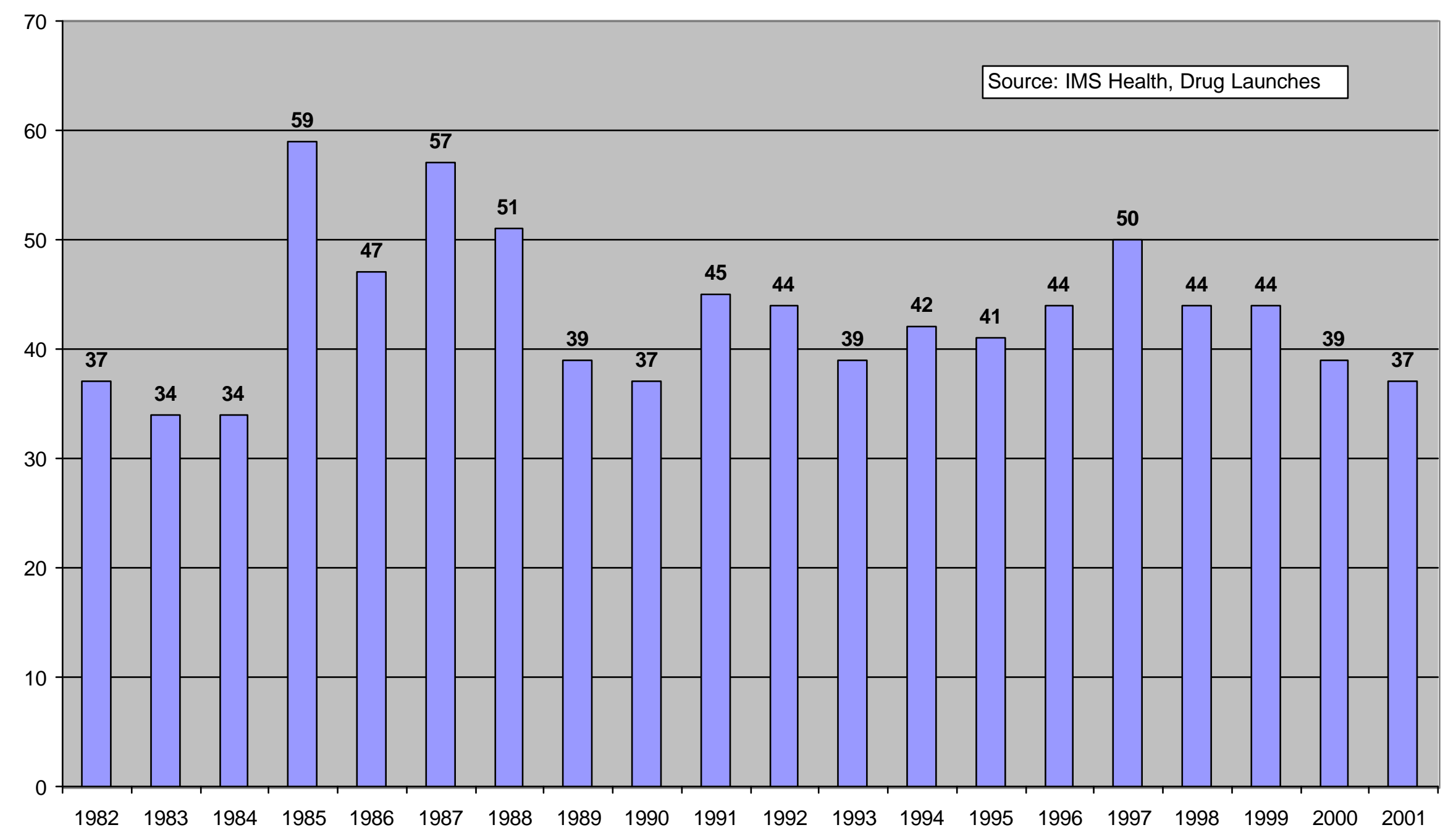




\section{Figure 6}

Distribution of new chemical entities launched, by principal therapeutic class

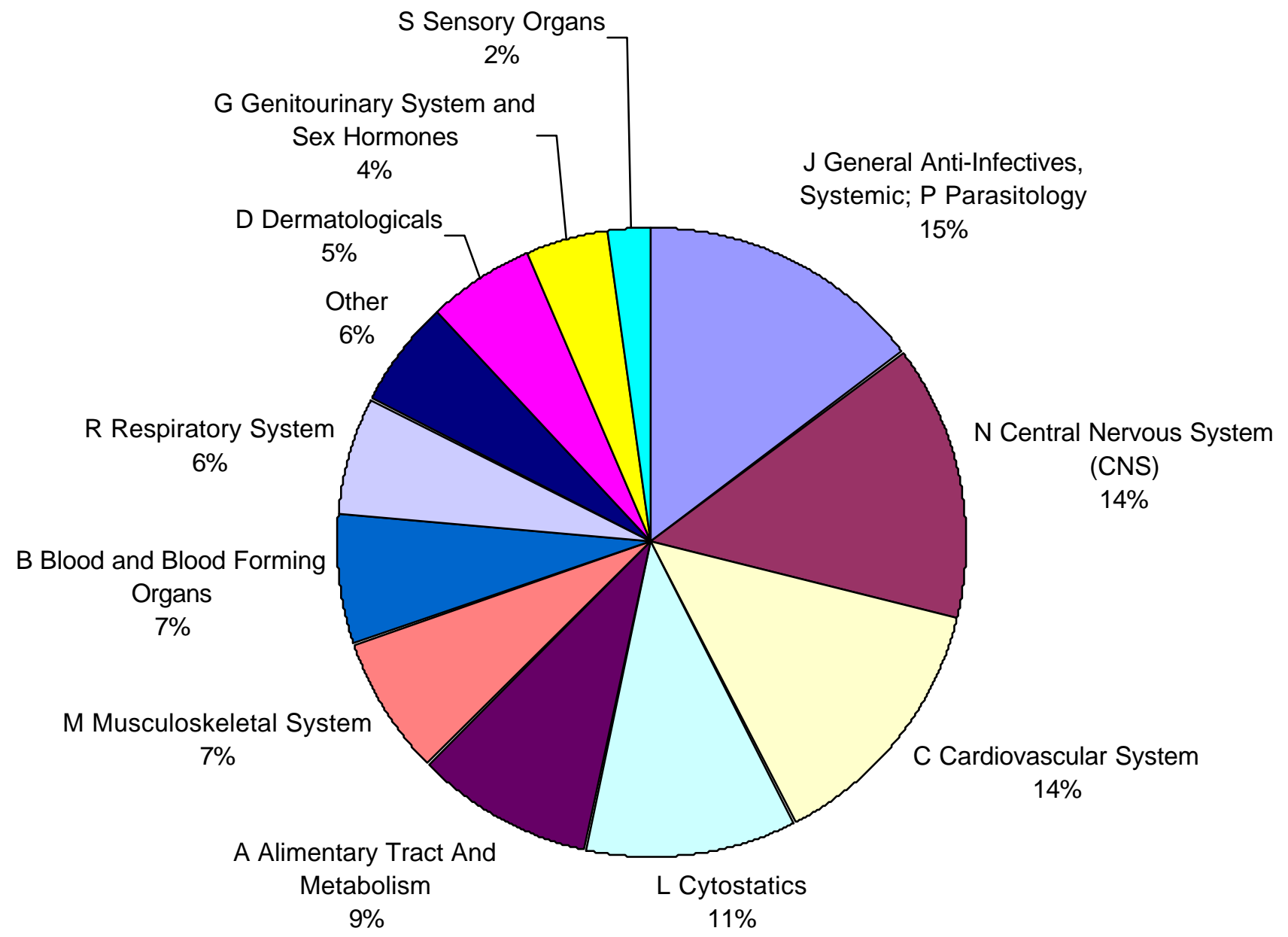




\section{Figure 7}

\section{Distribution of deaths, by cause}

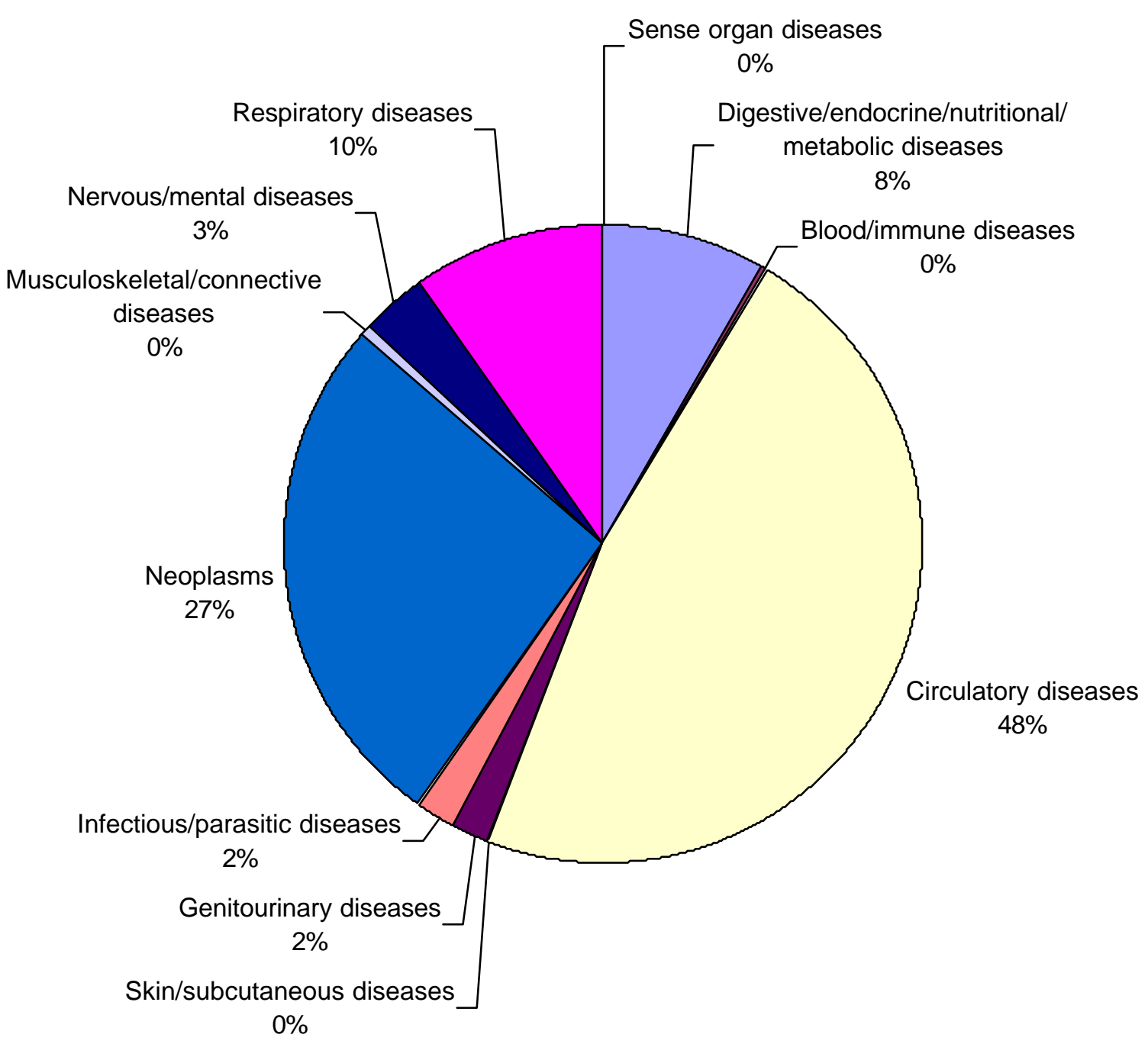


Figure 8

Estimates of $\beta_{\text {NCE }}$ for different lags between stock of NCEs launched and longevity

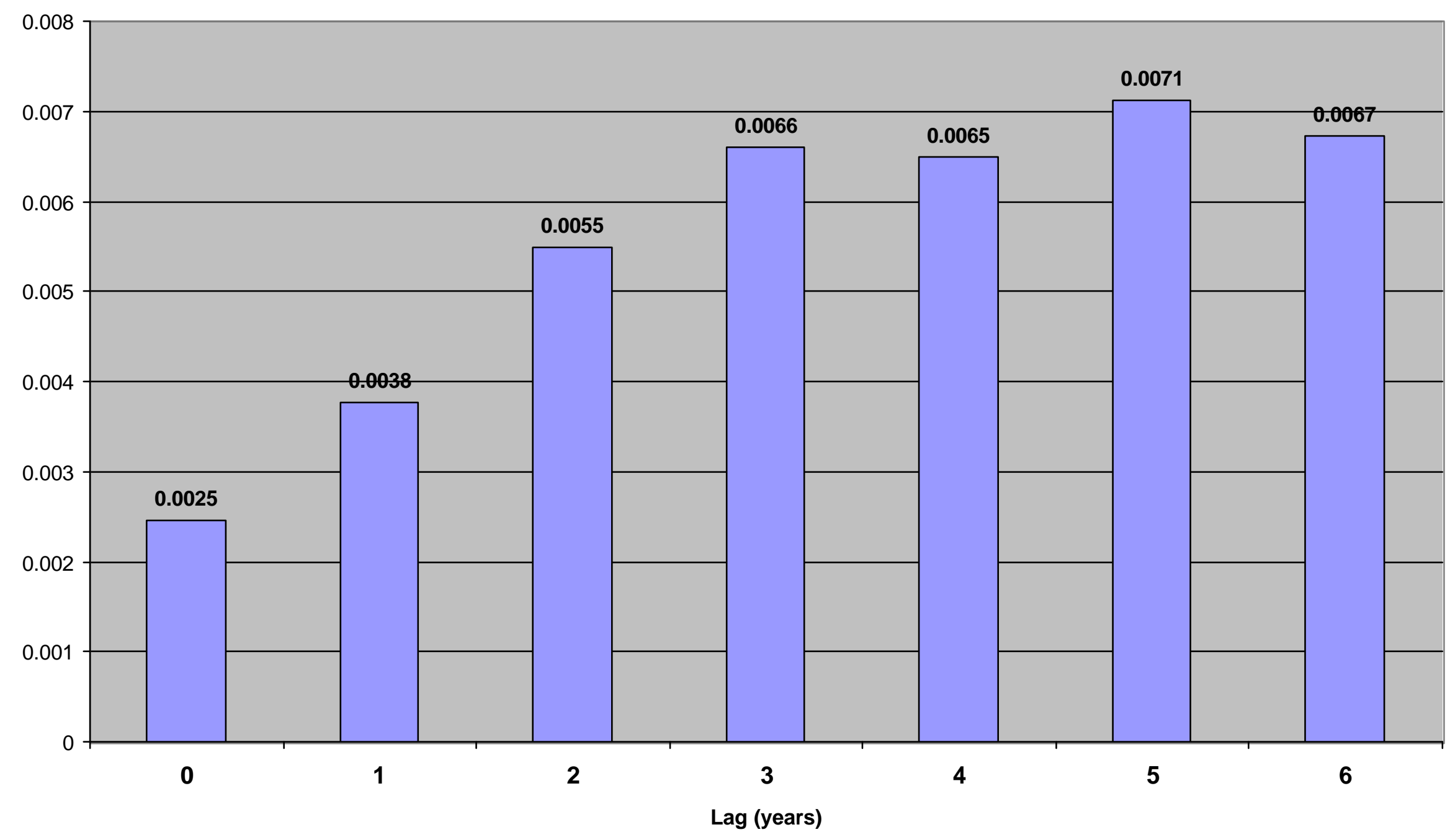


Figure 9

Figure 9

Estimates of $\beta_{\mathrm{NCE}}$ and $\boldsymbol{\beta}_{\text {expend }}$ at different lag values

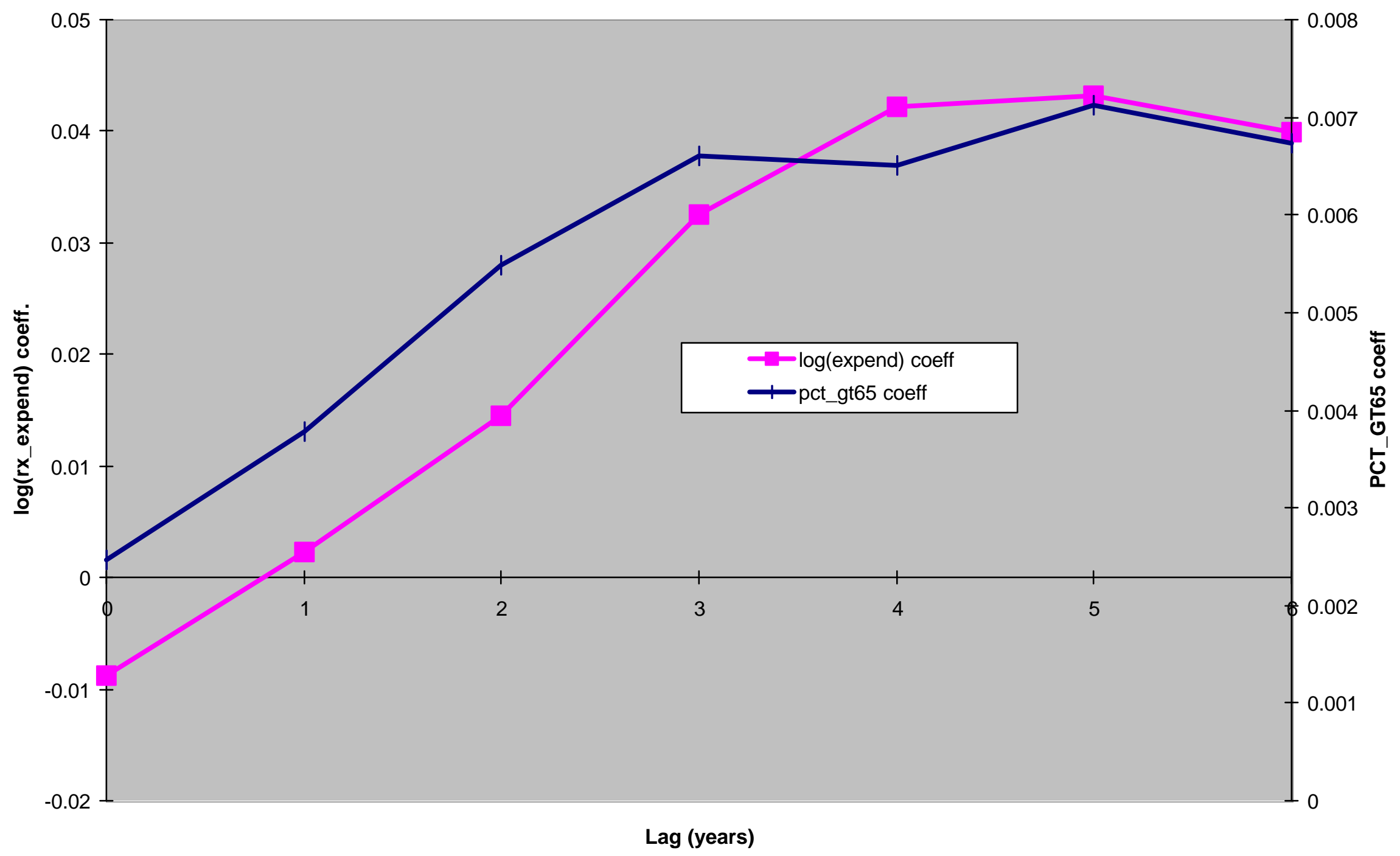


Figure 10

Contribution of NCE launches to increase in average life expectancy of the population since 1986

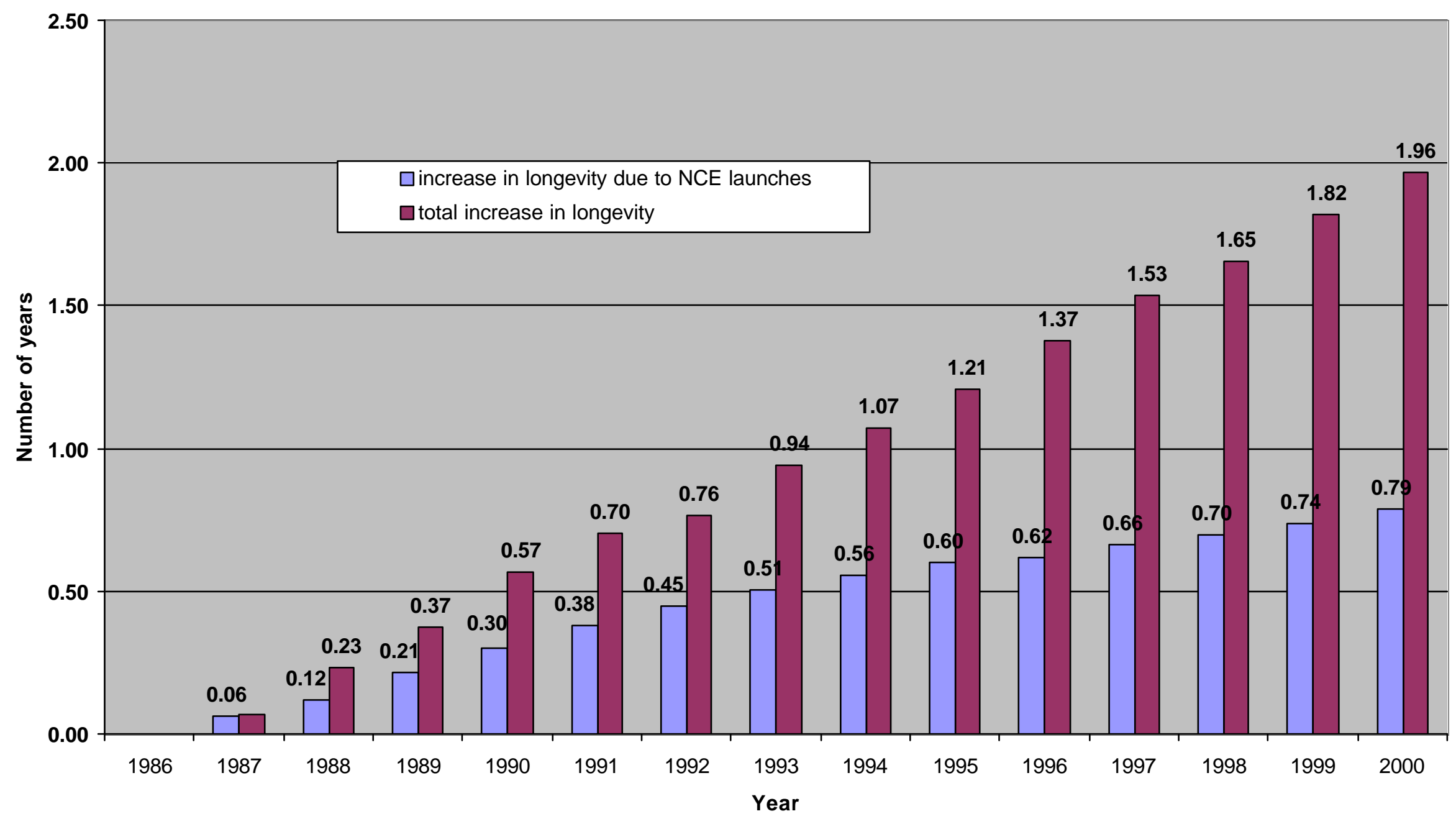

